\title{
Acute pulmonary embolectomy with cardiopulmonary bypass support
}

\author{
DANIEL J. WATERS, DO
}

WILLIAM E. STANLEY, DO

Deep venous thrombosis and pulmonary thromboembolism remain major sources of patient morbidity and mortality. The authors present the case of a 55-year-old man with a massive pulmonary embolism and subsequent hemodynamic decompensation who was successfully treated by open pulmonary embolectomy supported with cardiopulmonary bypass. Indications for embolectomy and patient selection as well as technical considerations are discussed.

(Key words: Venous thrombosis, pulmonary embolism, embolectomy, cardiopulmonary bypass)

Deep venous thrombosis and pulmonary embolism remain major causes of patient mortality and morbidity despite advances in diagnosis and therapy. ${ }^{1}$ Acute, massive pulmonary emboli may produce hemodynamic instability and profound systemic and cerebral hypoxemia. ${ }^{2}$ We present the case of a 55 -year-old man in whom a massive pulmonary embolus developed after the institution of thrombolytic therapy for iliofemoral venous thrombosis. The patient was successfully treated with open pulmonary embolectomy with the support of a pump-oxygenator. We discuss the technique of pulmonary embolectomy as well as considerations in patient selection.

From the Division of Cardiothoracic Surgery and the Iowa Cardiac Institute, Des Moines General Hospital, Des Moines, Iowa.

Reprint requests to Daniel J. Waters, DO, Mercy Heart Center, 84 Beaumont Dr, Mason City, IA 50401.

\section{Report of case}

A 55-year-old man was seen for evaluation of exertional dyspnea of 2 weeks' duration. The patient had no previous history of cardiac or pulmonary illness, chest pain, cough, or hemoptysis. He had had a deep venous thrombus in his right leg 12 years earlier. It had been treated for 3 months with oral warfarin therapy. There were no residual problems. The patient had a history of cigarette smoking of 50 pack-years. He denied having any recent or current lower extremity trauma, pain, or swelling. Results of physical examination and routine laboratory studies were unremarkable. Concentrations of arterial blood gases were within normal limits, as were the results of a resting surface electrocardiogram.

Results of a treadmill stress test suggested myocardial ischemia. Bilateral cardiac catheterization was performed by using a right femoral approach. Coronary artery anatomy was normal, as was left ventricular function. There was moderate pulmonary hypertension (right ventricular pressure, 50/ $7 \mathrm{~mm} \mathrm{Hg}$; pulmonary artery, $60 / 24 \mathrm{~mm} \mathrm{Hg}$ ). The patient was discharged from the hospital only to return 4 days later complaining of swelling and pain in the left leg.

Findings of a qualitative venous Doppler ultrasound study were highly suggestive of left deep venous thrombosis, and contrast venography of the left leg was performed (Fig 1). No contrast was visualized in the deep leg veins. Faint filling of the iliac vein from the greater saphenous vein was seen. A ventilation/perfusion scan was obtained. Results of the xenon washout ventilation scan were normal. The perfusion lung scan showed unmatched defects bilaterally, consistent with pulmonary emboli (Fig 2).

The patient was hospitalized and placed on absolute bed rest. Intravenous thrombolytic therapy 
for the iliofemoral deep venous thrombosis was instituted with streptokinase. An initial bolus injection of $250,000 \mathrm{IU}$ was followed by a continuous infusion of $100,000 \mathrm{IU} /$ hour. Six hours after thrombolysis was instituted, the patient got out of bed and had sudden, severe dyspnea and cough.

On measurement of arterial blood gases, the $\mathrm{PO}_{2}$ was $52 \mathrm{~mm} \mathrm{Hg}$ on a $2-\mathrm{L} / \mathrm{min}$ nasal cannula. The patient's room air $\mathrm{PO}_{2}$ had been $61 \mathrm{~mm} \mathrm{Hg}$. Dyspnea worsened and the patient was transferred to the intensive care unit. His arterial blood gas values worsened $\left(\mathrm{pH}, 7.31 ; \mathrm{PO}_{2}, 48 \mathrm{~mm} \mathrm{Hg} ; \mathrm{PCO}_{2}, 34\right.$ $\mathrm{mm} \mathrm{Hg}$; saturation, $79 \%$ ), and he required endotracheal intubation and mechanical ventilatory support. Hemodynamic instability ensued and required dopamine hydrochloride infusion. Despite vasopressor support and full ventilatory support with a fractional concentration of oxygen in inspired gas $\left(\mathrm{FIO}_{2}\right)$ of 1.0 , the systolic blood pressure could not be maintained above $90 \mathrm{~mm} \mathrm{Hg}$, nor could the arterial $\mathrm{PO}_{2}$ be kept above $60 \mathrm{~mm} \mathrm{Hg}$. The patient was transferred to the cardiac surgery unit.

Median sternotomy was performed. The right atrium and ventricle were tense and distended. The left ventricle contracted normally. On aortic cannulation, dark, desaturated blood was obtained.

The patient was placed on cardiopulmonary bypass. The ascending aorta was cross-clamped and diastolic arrest induced with cardioplegic solution. A longitudinal incision was made in the main pulmonary artery (Fig 3). No thrombus material was evident there. The pleural spaces were entered bilaterally; the lung parenchyma was manually compressed. With the use of curved Randall stone forceps, several large clots were removed from the right and left pulmonary arteries (Fig 4). The pulmonary arteriotomy was closed with continuous nonabsorbable monofilament sutures (Fig 5).

The patient was separated from cardiopulmonary bypass without difficulty, and arterial oxygen saturation improved dramatically. After decannulation, a Greenfield inferior vena cava filter cartridge was passed through the right atriotomy and guided into the inferior vena cava. Fluoroscopy guided filter placement and discharge. The chest was closed, the patient was returned to the intensive care unit, and a low-dose infusion of dopamine hydrochloride was started. Hemodynamic parame-
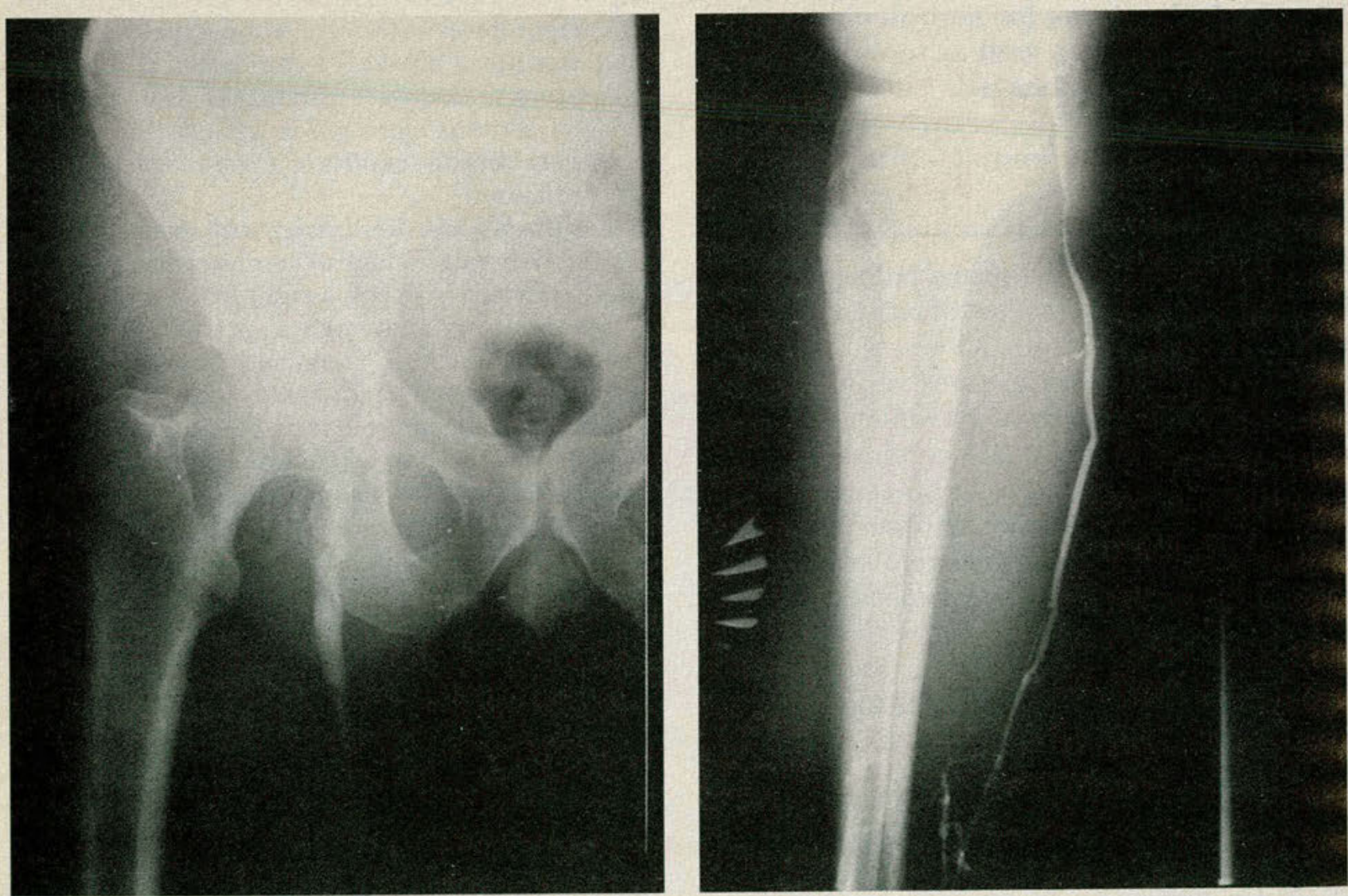

Figure 1. Lower extremity contrast venograms showing faint visualization of the iliac and femoral veins (left frame) via the superficial saphenous system (right frame). The remainder of the deep venous system is occluded. 


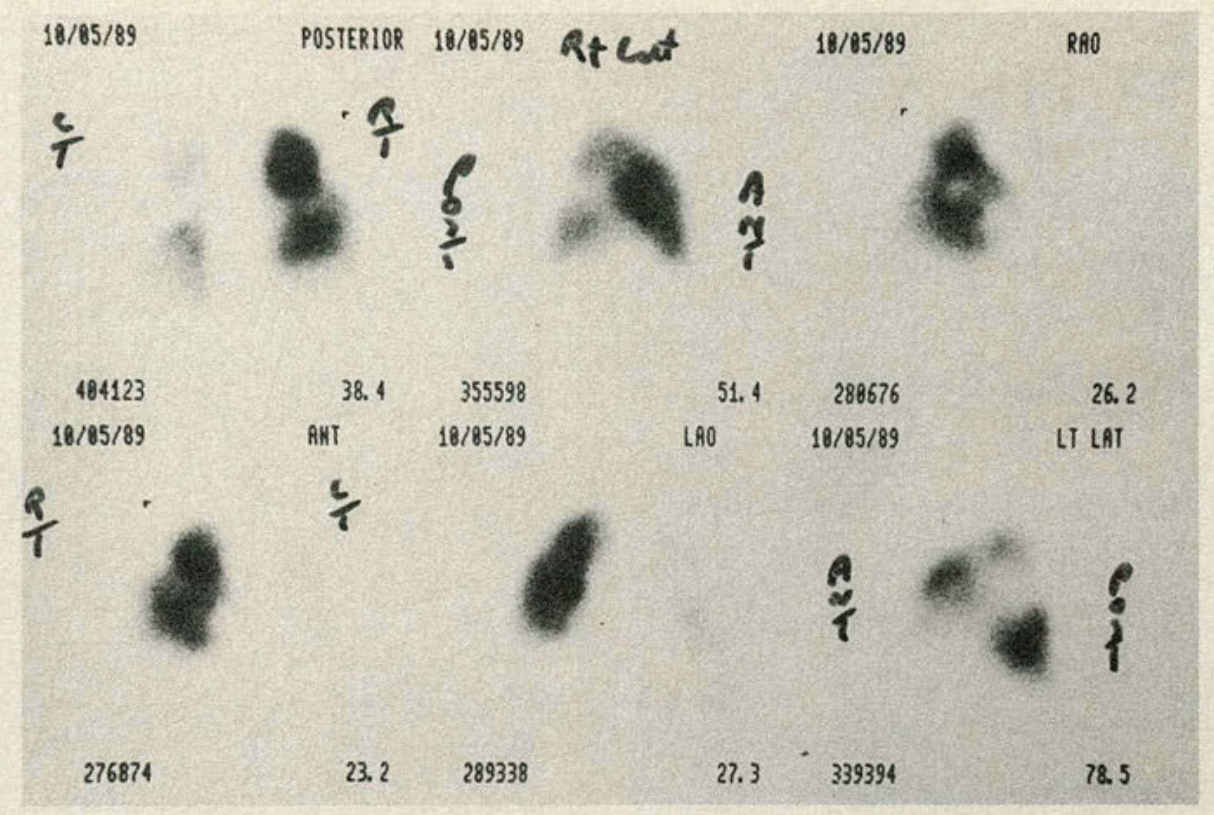

Figure 2. Perfusion lung scan showing bilateral defects consistent with pulmonary emboli. These defects were unmatched on ventilation lung scan.

ters were stable and arterial oxygenation was excellent.

The patient was extubated on the first postoperative day and had an uncomplicated convalescence. He was discharged from the hospital 9 days after surgery. Follow-up examinations have shown him to be well, and his dyspnea has abated.

\section{Discussion}

Acute, open pulmonary embolectomy remains a controversial procedure.$^{3-5}$ The first attempts at surgical removal of pulmonary emboli were reported by Trendelenburg in 1908, when he described the operation that bears his name. He was unable, however, to report any survivors of the procedure. ${ }^{5,6}$ Successful embolectomy was first reported by Kirschner (a student of Trendelenburg) in $1924 .{ }^{7}$ Scattered clinical reports appeared over the next four decades, with poor patient survival. ${ }^{8,9}$ Because it had a high mortality rate, the procedure was not widely used.

The development of clinically applicable cardiopulmonary bypass spurred a renewed interest in surgery for pulmonary embolus. Over the next 30 years, the number of reports of successful procedures burgeoned, although the mortality rate remained significant. ${ }^{10-16}$ Refinements in cardiopulmonary bypass and myocar- dial protection have furthered the acceptability of the procedure.

Patient selection based on preoperative hemodynamic and oxygenation data correlates well with a successful surgical outcome. ${ }^{17}$ Patients who have experienced cardiac arrest have been successfully treated with surgery, but their overall survival rate is lower than that of patients without an episode of arrest. ${ }^{18}$

Pulmonary embolectomy has been performed in the modern era without cardiopulmonary bypass support. ${ }^{19}$ In an analysis of 651 cases in the literature, however, Del Campo ${ }^{20}$ found that survival was improved in patients who were supported with a pump-oxygenator. His review gives a concise analysis of survival data in published series. ${ }^{20}$

Surgical technique using cardiopulmonary bypass is relatively standard. The method of cannulation may vary with patient status, as may the timing of cannulation and bypass (eg, femoral-femoral cannulation before sternotomy). ${ }^{14,20,21}$ The current refinements in percutaneous portable bypass techniques may further expand the pool of patients who are candidates for embolectomy.

Once cardiopulmonary bypass is established and aortic cross-clamping achieved, the main 


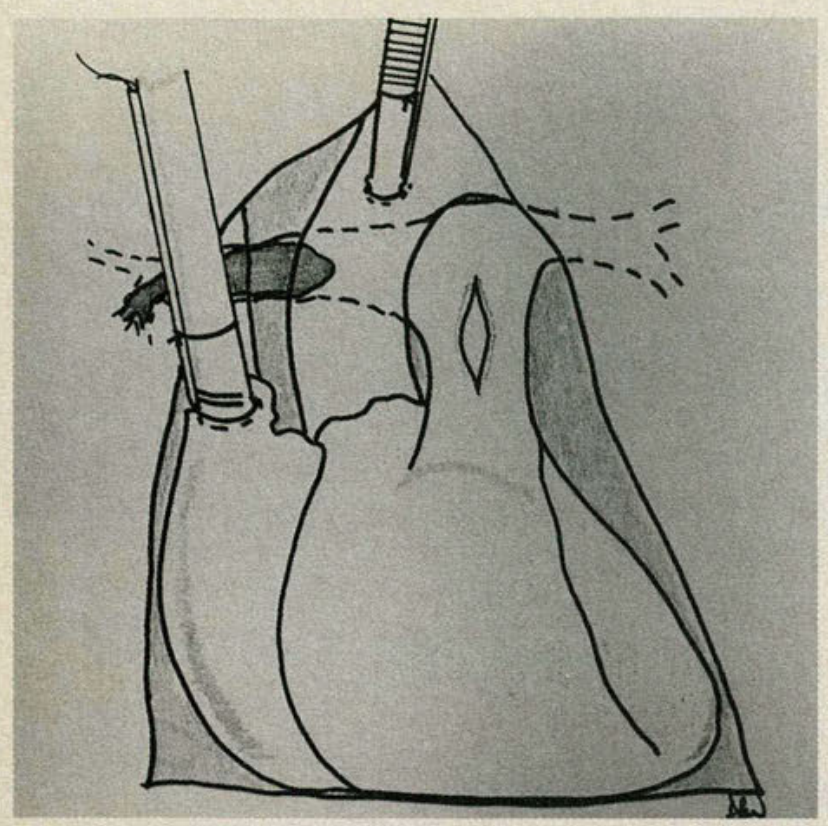

Figure 3. Placement of pulmonary arteriotomy for embolectomy. The main pulmonary artery is incised above level of valve and below arterial bifurcation.

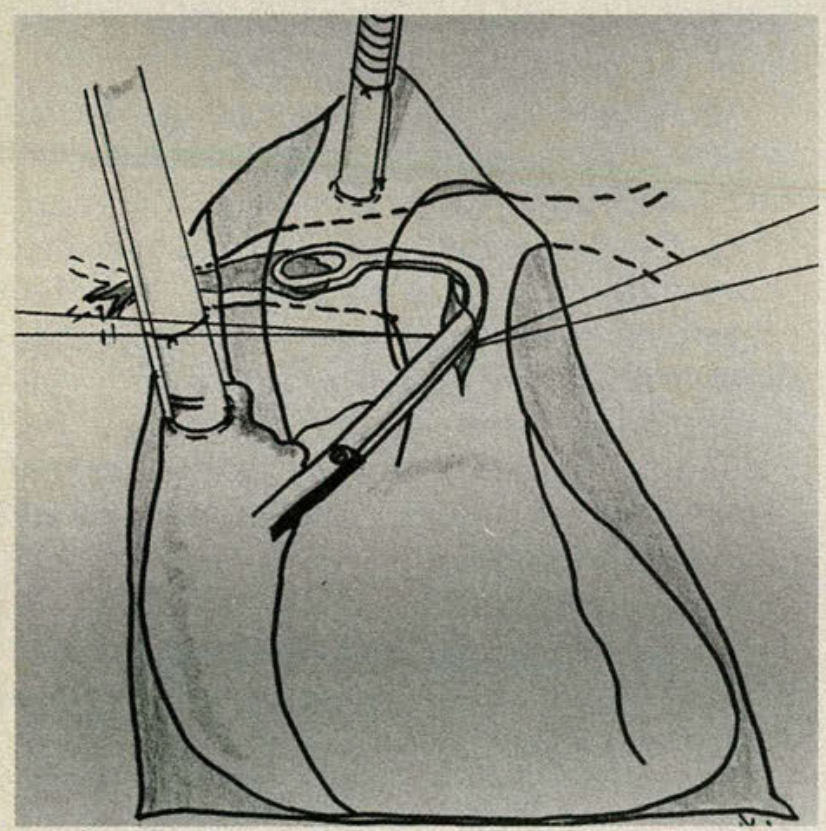

Figure 4. Use of curved stone forceps to grasp and extract thrombus from the right pulmonary artery.

pulmonary artery is incised longitudinally and monofilament stay sutures are placed in each side of the arteriotomy for traction. Thrombus material may not be immediately seen in the lumen. We find that a curved stone forceps works nicely for extraction of clot from the right and left pulmonary trunks and their

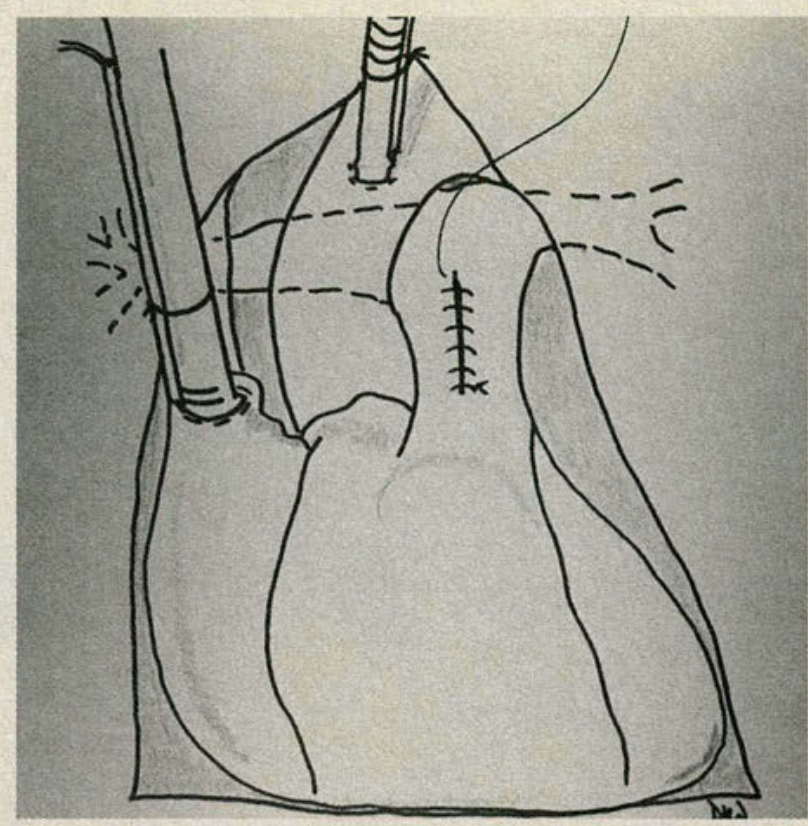

Figure 5. After embolectomy, pulmonary arteriotomy is closed with continuous nonabsorbable monofilament sutures.

branches. Manual compression of the lungs helps to "milk" the distal aspect of the clot back into the main arterial branches where it can be easily extracted. ${ }^{10,21}$ Beckman and colleagues ${ }^{22}$ described direct visualization of the arterial lumen by use of a flexible fiberoptic choledochoscope as a valuable adjunct to "blind" extraction with forceps or an embolectomy catheter. ${ }^{22}$

The pulmonary arteriotomy is closed primarily with continuous monofilament sutures. The procedure can be performed without cardioplegic arrest. ${ }^{14}$

Some authors describe the concomitant use of a procedure that interrupts the vena cava to reduce the risk of recurrent embolism..$^{14,21}$ In our patient, we elected to use the Greenfield filter because of the ease of intraluminal placement without the need for a second operative incision. The right atrial cannulation site provides superb access for passage of the relatively bulky filter cartridge.

Difficulty in postoperative management is usually related to the presence of pulmonary infarction, complications associated with cardiopulmonary bypass, or profound preoperative cerebral anoxia with resultant neurologic impairment. ${ }^{14,19}$ 
The role of preoperative pulmonary angiography is often affected by the rapidity of hemodynamic and respiratory deterioration. Pulmonary angiograms should be obtained when the clinical situation permits and can be performed while the patient is supported on portable cardiopulmonary bypass. ${ }^{14,20,21,23}$ In patients with documented deep venous thrombosis undergoing thrombolytic therapy, sudden cardiopulmonary collapse is associated with the occurrence of a massive pulmonary embolism, and surgery may be undertaken without delay for arteriography. ${ }^{21,24}$

It is interesting to note that it was a case of fatal pulmonary embolism in a young patient that spurred John Gibbon ${ }^{25}$ to seek a method that would artificially both pump and oxygenate the blood. His development of the pump-oxygenator and clinical cardiopulmonary bypass ushered in a new surgical era. While the treatment of congenital and acquired cardiac defects seems to have been the major beneficiary of bypass technology, there is a pleasing irony in its use to rescue patients from the very malady that fostered its invention.

\section{Comment}

Emergency open pulmonary embolectomy can be a lifesaving procedure in properly selected patients. Combined with the use of cardiopulmonary bypass, it is a valuable treatment option for patients who have massive pulmonary embolism associated with hemodynamic compromise and refractory hypoxemia.

\section{References}

1. Mohr DN, Ryu JH, Litin SC, et al: Recent advances in the management of venous thromboembolism. Mayo Clin Proc 1988;63:281-290.

2. Gorham LW: A study of pulmonary embolism. Arch Intern Med 1961;108:22-29.

3. Gray HH, Miller GAH: Pulmonary embolectomy is still appropriate for a minority of patients with acute massive pulmonary embolism. Br J Hosp Med 1989;41:467-468.
4. Clarke DB: Pulmonary embolectomy has a well defined and valuable place. $B r J$ Hosp Med 1989;41:468-469.

5. Oakley CM: There is no place for acute pulmonary embolectomy. Br J Hosp Med 1989;41:469-470.

6. Trendelenburg F: Ueber die operative Behandlung der Embolie der Lungarterie. Arch Klin Chir 1908;86:686-700.

7. Kirschner M: Ein durch die Trendelenburgsche Operation geheilter Fall von Embolie der Art pulmonalis. Arch Klin Chir 1924;133:312-359.

8. Churchill ED: Mechanism of death in pulmonary embolism with comments on Trendelenburg operation. Surg Gynecol Obstet 1934;59:513-517.

9. Lewis I: Problems in diagnosis and management of pulmonary embolism, in Harley HR (ed): Modern Trends in Cardiac Surgery. London, England, Butterworth Co, Ltd, 1960, pp 6466.

10. Cooley DA, Beall AC, Alexander JK: Acute massive pulmonary embolism: Successful surgical treatment using temporary cardiopulmonary bypass. JAMA 1961;177:283-286.

11. Sharp EH: Pulmonary embolectomy: Successful removal of a massive pulmonary embolus with the support of cardiopulmonary bypass. Ann Surg 1962;156:1-4.

12. Tschirkov A, Krause E, Elert O, et al: Surgical management of massive pulmonary embolism. $J$ Thorac Cardiovasc Surg 1978;75:730-733.

13. Clarke DB: Pulmonary embolectomy reevaluated. Ann $R$ Coll Surg Engl 1981;63:18-24.

14. Mattox KL, Feldtman RW, Beall AC, et al: Pulmonary embolectomy for acute massive pulmonary embolism. Ann Surg 1982;195:726-731.

15. Satter P: Pulmonary embolectomy with the aid of extracorporeal circulation. Thorac Cardiovasc Surg 1982;30:31-35.

16. Berger RL: Pulmonary embolectomy with preoperative circulatory support. Ann Thorac Surg 1973;16:217-227.

17. Glassford DM, Alford WC, Burrus GR, et al: Pulmonary embolectomy. Ann Thorac Surg 1981;32:28-32.

18. Clarke DB, Abrams LD: Pulmonary embolectomy: A 25 year experience. J Thorac Cardiovasc Surg 1986;92:442-445.

19. Weatherford SC, Lawrie GM: Trendelenburg pulmonary embolectomy for cardiac arrest secondary to massive pulmonary embolism. Can J Surg 1986;29:383-384.

20. Del Campo C: Pulmonary embolectomy: A review. Can $J$ Surg 1985;28:111-113.

21. Robison RJ, Fehrenbacher J, Brown JW: Emergent pulmonary embolectomy: The treatment for massive pulmonary embolus. Ann Thorac Surg 1986;42:52-55.

22. Beckman D, Solmos B, Herod G, et al: Intraoperative pulmonary angioscopy using the flexible fiberoptic choledochoscope. Ann Thorac Surg 1986;41:563-564.

23. Gray HH, Miller GAH, Paneth M: Pulmonary embolectomy: Its place in the management of pulmonary embolism. Lancet 1988;1:1441-1445.

24. Goldsmith JC, Lollar P, Hoak JC: Massive fatal pulmonary emboli with fibrinolytic therapy. Circulation 1982;64:10681069.

25. Gibbon JH: The development of the heart-lung apparatus. Am J Surg 1978;135:608-620. 


\section{Turning}
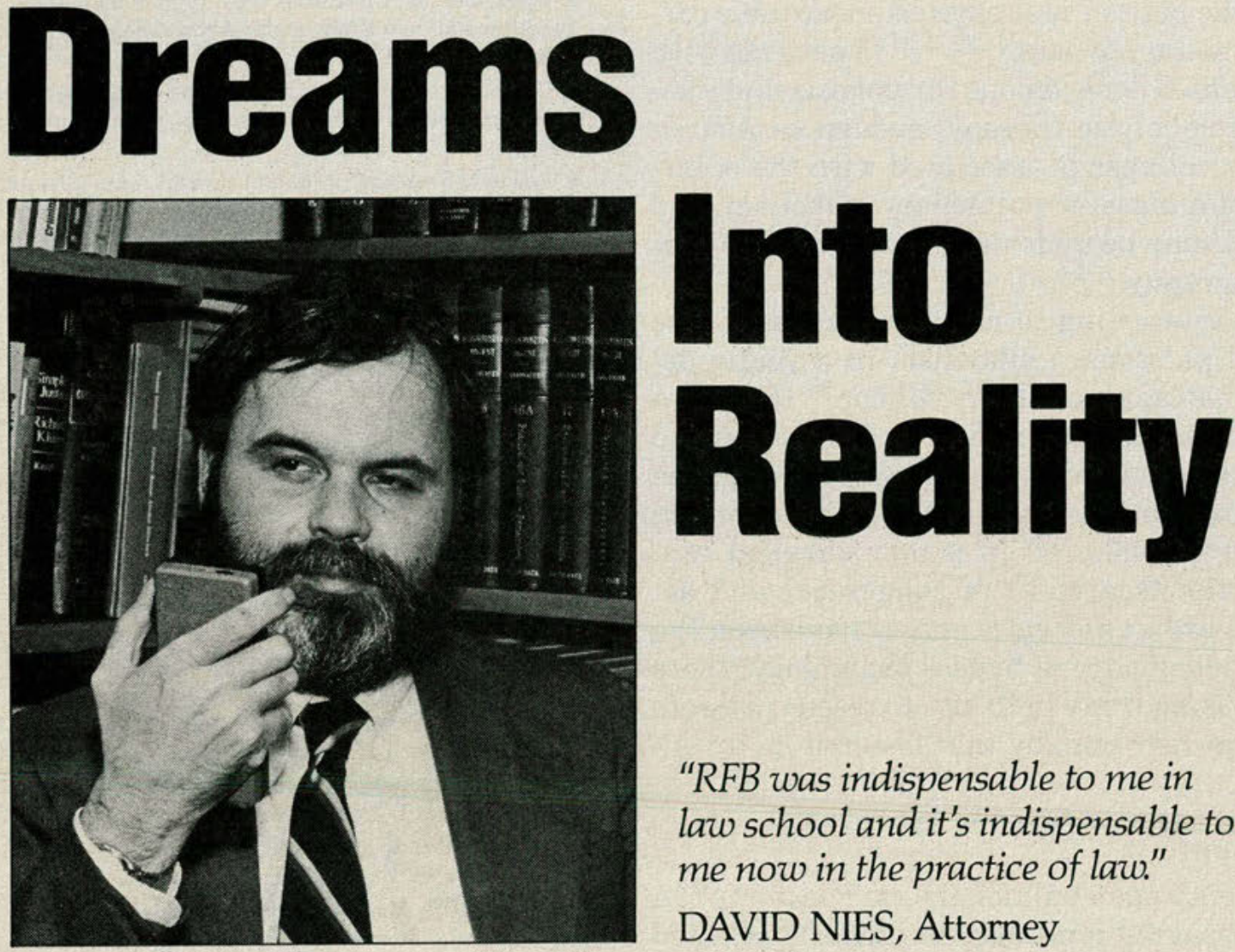

"RFB was indispensable to me in law school and it's indispensable to me now in the practice of law."

DAVID NIES, Attorney

\section{D}

reams of a successful career and an independent future have become reality for thousands of blind or print-handicapped persons with the help of Recording for the Blind.

Since 1948 Recording for the Blind has provided more than one million recorded educational books to over 100,000 individuals. Not only to students, but also to business and professional people such as attorney David Nies. All free of charge.

But each year more students and professionals need recorded books. And they need increasingly technical and specialized texts. By joining RFB's corps of recording studio volunteers or giving a tax-deductible donation, you can help more dreams become reality.

To find out more about this service and how you can help, write:

Recording for the Blind

20 Roszel Road

Princeton, New Jersey 08540

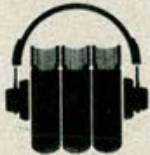

